\title{
METÁFORAS INFELIZES NO DIREITO PENAL
}

\author{
UNHAPPY METAPHORS IN CRIMINAL LAW
}

Friedrich-Christian Schroeder ${ }^{* *}$

\begin{abstract}
Resumo:
Nesse artigo, F.-C. Schroeder analisa o lugar das metáforas no caso de antecipação da punibilidade denunciada por Günther Jakobs e suas conseqüências para o direito penal.
\end{abstract}

Palavras-chave: Metáforas. Antecipação da punibilidade. Günther Jakobs.

\begin{abstract}
:
In this paper, F.-C. Schroeder analyses the place of the metaphors in the case of anticipation of punishable offences from the denunciation of Günther Jakobs on and its consequences for the penal law.
\end{abstract}

Keywords: Metaphors. Anticipation of punishable. Günther Jakobs.

$\mathrm{I}$.

Em sua Opus magnum dedicada "às normas" Karl Binding evidenciou:

A proibição de lesionar inibe a causação de um resultado não desejado, constituindo a mesma um escudo que protege eficazmente ao bem ou ao direito. Contudo, a lei empurra as fronteiras de sua fortificação para adiante, de tal forma que os bens não apenas são resguardados por uma simples muralha, mas sim que a mesma se duplica, chegando inclusive, em ocasiões, a se triplicar. Desta maneira, ao primeiro cinturão de proteção, que significa a proibição de causação, segue-se um segundo: o da exposição a perigo [...] Mas sem se conformar a isso, o âmbito de proteção se distancia ainda mais do bem tutelado, criando-se finalmente, com o objetivo de inibir a ação humana, um terceiro tipo de proibição: o das ações em que o resultado conseqüente não seria sequer relevante $[\ldots]$. $^{1}$

Na obra dele Lehrbuch des Gemeinen Deutschen Strafrechts, o mesmo autor explicou:

- Tradução autorizada pelo autor de Missglückte Metaphern im Strafrecht, publicado In: CANCIO MELIÁ et al. (Org.) Festschrift für Günther Jakobs, Berlin, Carl Heymanns, 2007, p. 627-633, por Andres Falcone e Eduardo Saad-Diniz. De uso recorrente no texto, a expressão "homenageado" refere-se a Günther Jakobs.

" Professor Dr. h. c. mult. de Direito Penal da Faculdade de Direito da Universidade de Regensburg, Alemanha

1 Die Normen und ihre Übertretung, 3. ed., v. 1, 1916, p. 326 [grifo do autor]. 
É chamativa a forma em que se busca o retrocesso da consumação delitiva a um estado anterior, o do delito recém tentado. A impaciência do legislador não o permite chegar à consumação. ${ }^{2}$

O fato de que Binding refira-se à mesma situação em primeiro lugar como um empurrão para frente e posteriormente como retrocesso merece apenas uma anotação marginal. Estas expressões colheram, na oportunidade em que foram expostas, um semnúmero de elogios. No entanto, tempos depois, as mesmas foram objeto de uma inversão em seu significado e de um excesso provocativo efusão no pensamento político-criminal do nacional-socialismo. Logo após Karl Klee haver publicado em 1933 o Denkschrift des Nationalsozialistisches Strafrecht, no qual propunha a redução da esfera de proteção do direito a uma efetiva tutela do bem jurídico, ${ }^{3}$ seguiram as reflexões de Roland Freisler, que em 1934, na obra Denkschrift des Zentralausschusses der Strafrechtsabteilung der Akademie für Deutsches Recht über die Grundzüge eines Allgemeinen Deutschen Strafrechts, afirmava o seguinte:

Se o direito pretende cumprir sua finalidade, isto é, a tutela de bens jurídicos, então deve combater pela raiz a vontade delinqüente; e isso apenas pode ocorrer se a linha de defesa do Estado adianta-se até o ponto em que, no caso concreto, o impedimento do dano iminente ainda seja possível. Conseqüentemente, deve-se atacar no preciso instante em que se concebeu a decisão de cometer um ilícito e a mesma se manifestou no mundo exterior $[\ldots] .^{4}$

No relatório sobre o trabalho na comissão oficial sobre Direito Penal de 1935, Freisler perguntou "onde se deve constituir a ativa linha de defesa do Estado contra os elementos negadores e ameaçadores do ordenamento" 5

Com estes pretextos, a política criminal nacional-socialista exigiu a criação de tipos penais de empreendimento, de aptidão e de perigo.

Questionamentos desta natureza se manifestam ainda na atualidade, ainda nos dias de hoje a direção de embate é a oposta, já que a postura majoritária entende que o direito penal como direito penal de autor deve esperar a lesão do bem jurídico. ${ }^{6}$ No caminho contrário, entretanto, Jakobs reprova o pensamento tutelar do bem jurídico,

\footnotetext{
v. 1, 2. ed. 1902, p. 11 [grifo do autor].

p. 123 e ss.

SCHRIFTEN DER AKADEMIE FÜR DEUTSCHES RECHT, v. 1., p. 13 [grifo do autor].

ROLAND, Freisler. Das kommende deutsche Strafrecht. Allgemeiner Teil, 2. ed., 1935, p. 25.

HASSEMER, Einführung in die Grundlagen des Strafrechts, 2. ed. 1990, p. 276; WEBER, suplemento especial de ZStW, 1987, p. 2.
} 
deixando aberta a questão de por que se deve esperar a efetiva lesão. ${ }^{7}$ Criticamente, sustenta-se que o atual direito penal protege antes, no prelúdio da lesão. ${ }^{8}$

Fala-se de "criminalização no prelúdio da lesão do bem jurídico" ${ }^{9}$ de "tipos penais de antecipação", ${ }^{10}$ da "antecipação da proteção do direito penal" etl etc. O primeiro foi o nome que recebeu a destacada apresentação do homenageado em 1985.'2

II.

Todas estas formulações são chamativas e sugestivas, mesmo que passe por alto o modo de proceder e a natureza mesma do direito penal. Estamos falando aqui de metáforas antropomorfas, vinculadas, sobretudo à esfera bélico-militar. As mesmas empregam referências tanto espaciais ("empurrão para frente" "distanciamento do bem jurídico tutelado" "prelúdio") como temporais ("impaciência" "impedimento ainda possível do dano iminente" "esperar" "antes"), ${ }^{13}$ de tal forma que parecia que estivéssemos enfrentando o invasor e tivéssemos que tomar as armas e tentar avançar espacial e temporalmente. Uma situação de defesa desta natureza apenas é tolerada no caso de que a agressão ilegítima seja atual ou iminente; desta forma o direito penal, mediante institutos como a legítima defesa, permite que a agressão seja interrompida ou prevenida, tornando admissível ao direito de polícia. Por isso dizemos que o direito penal apenas é útil em face de agressão mediata ou futura.

Mais interessante do que a distinção referida ao destinatário entre prevenção geral e especial, é a diferenciação, referida ao método, entre a prevenção através de ameaça e da execução da sanção. Através desta última, busca-se impedir a produção do injusto mediante a subtração da liberdade do agente (a qual é pressuposto da ação delitiva), a ressocialização, a dissuasão do autor e de outras pessoas e finalmente a confirmação da validade normativa. ${ }^{14}$ Mas a execução da sanção penal pressupõe não apenas a já finalizada consumação, ou, se o caso, tentativa, senão as mais ou menos prolongadas

Was schützt das Strafrecht: Rechtgüter oder Normgeltung? In: Aktualität und Entwicklung der Strafrechtwissenschaft, Libro homenaje a Saito, 2003, p.780 e ss. 770 [grifo do autor].

8 PRITTWITZ, Strafrecht und Risiko, 1993, p. 245.

9 Ese fue el nombre de uno de los temas en las Jornadas de doctrina de Derecho Penal alemán celebradas en Frankfurt a. M. en 1985.

10 WEBER, Suplemento especial de ZStW, 1987, p.5.

"Ese era el tema del grupo de especialistas en Derecho Penal comparado en las Jornadas de la Sociedad para la comparación del Derecho 1985, Suplemento especial de ZStW, 1987.

12 JAKOBS, ZStW 97 (1985), p. 751 ss.

13 "Arrancar de raíz" en Freisler es una metáfora híbrida.

14 JAKOBS, Strafrecht AT, 2da. Ed., 1991, p. 1/1 ss. Introducirnos en los pormenores de la teoría de la pena en Jakobs significaría exceder los límites del presente trabajo. "El ejercicio en la aceptación de consecuencias" (ZStW tomo 101 [1989], p, 516 ss.; Strafrecht AT, p. 1/15) que luego fueran incorporadas por Jakobs a las finalidades del Derecho Penal significan, en realidad, el ejercicio del abuso de derecho. 
etapas de investigação e julgamento. Por isso sustentamos que a crítica à "espera" da lesão de bem jurídico carece totalmente de sentido, já que ao momento da imposição da sanção, o resultado foi produzido há tempo ou jamais se produzirá. ${ }^{15}$ Por conseguinte, destaca-se a incongruência naquela formulação de Freisler: "deve-se atacar no preciso instante em que se concebeu a decisão de cometer um ilícito e a mesma se manifestou no mundo exterior" já que consideramos que o autor confunde aqui grosseiramente o direito penal com o direito de polícia. A prevenção de delitos através da ameaça penal se situa temporalmente no instante em que o agente decide cometer o ilícito, por isso é que é irrazoável supor que a mesma "espera" que aconteça o resultado. A tentativa requer vontade de consumação, já que o que se procura não é a produção de mero delito tentado, mas sim do consumado, ainda que seja minimamente a título de dolo eventual. A ameaça penal atua, se é que o faz em algum momento, apenas no instante da tentativa. É conseqüente destacar que a incriminação da tentativa não consegue que o agente se abstenha de produzir a ação típica, justamente porque aquela não se concebe por si só, senão como uma tentativa falida de produzir o delito consumado, de forma que calcular sua punibilidade com o objetivo de "avançar na línea de defesa" resultaria por demais desacertado.

Então devemos persistir em tentar descobrir quais são os efeitos político criminais que se perseguem por meio da punição da tentativa, questão que apenas foi abordada pela doutrina, a qual sim se dedicou com exaustão a indagar sobre as causas da mesma, as que se resolvem, na maioria dos casos, atendendo ao direito positivo. ${ }^{16}$ A punibilidade da tentativa tem sua razão de ser na prevenção que gera a execução da sanção, e isto é assim, em primeiro lugar, porque por meio dela se confirma a validade da norma com independência da produção de resultado; em segundo lugar porque estatisticamente a confirmação jurídica da norma é maior do que pela mera punição da consumação, e finalmente porque através da execução se conquista a subtração estatal da liberdade, educação e dissuasão individual de pessoas perigosas. Com isto se consegue o fortalecimento efetivo da proteção de bens jurídicos, ainda que sem a pretendida antecipação espacial ou temporal. Por outra parte, através da ameaça que produz a sanção da consumação se adianta a tutela do bem jurídico ao momento da ação; adiantar a tutela seria ainda mais impossível.

Algo similar ocorre com os delitos de empreendimento, já que a pretendida "antecipação da proteção penal" pelos mesmos é impossível. Se coincidimos quanto à importância da impunidade na desistência voluntário de consumar o delito, ${ }^{17}$ coincidiremos também quanto à exclusão da possibilidade de desistência nos delitos de empreendimento;

is Esto a excepción de los delitos calificados por el resultado e las consecuencias tardías (sobre ello Jakobs [n. 14] p. 7/81).

16 A título exemplificativo, Roxin, Strafrecht AT/II, 2003, §29 Rn. 9 ss.

17 Com reservas JAKOBS, (nota 15), p. $26 / 5$. 
não é reforçada, mas sim que, do contrário, debilita-se o poder de proteção do direito penal (o que faz que às vezes o legislador restabeleça dita possibilidade pelas disposições especiais).

Também são válidas estas reflexiones para aqueles que identificam o dolo nos delitos de perigo com o dolo condicionado nos delitos de lesão, ${ }^{18}$ inclusive nos delitos dolosos de perigo concreto. Caso se critique esta postura, ${ }^{19}$ dá-se espaço para os delitos dolosos de lesão, mas não nos de perigo. O ponto em comum entre ambos, o perigo, situase em realidade no momento anterior à lesão, mas o que é verdadeiramente interessante, $\mathrm{e}$ incluímos aqui os delitos culposos de perigo, não é a (mínima) antecipação temporal, mas sim a expansão da punibilidade ainda naqueles casos em que "todo haja saído bem", ${ }^{20}$ ou nos que existem problemas de determinação do resultado lesivo, ou finalmente nos que não parece nítida a relação de causalidade. ${ }^{21}$ Nestes casos, não é que a lei prescinde da espera de lesão, ${ }^{22}$ senão que se apena sem sequer considerar sua realização.

Menos capciosa é a afirmação de que a punibilidade ou a criminalização se adiantam. Isto também se trata de uma metáfora, permanecendo na penumbra se a mesma se concebe em termos temporais ou espaciais. Em ambos os casos não se vincula à proteção do bem jurídico, pelo contrário ao desenvolvimento da conduta punível que abarca a planificação, a celebração e a produção do resultado típico. Não é, portanto, a proteção do bem jurídico a que se antecipa, mas sim o campo de punibilidade a um estádio anterior da mesma conduta típica. Neste sentido deve criticar-se aquela formulação que sustenta que sem a antecipação da punibilidade o ataque se estenderia até a produção de resultado típico. Não devemos perder de vista que estas postulações não buscam meramente adiantar a punibilidade, senão, pelo contrário, expandir o campo de ação do direito penal.

Tampouco podemos aqui passar por alto aqueles enunciados que postulam a tutela de bens juridicos anteriores. Conseqüentemente, devemos apontar que no direito ambiental a proteção da água e do ar significa, em última instância, a proteção do ser humano, de tal forma que a lesão destes bens jurídicos se produz não só lógica como também temporalmente, antes que a lesão da saúde dos homens. Sem embargo, deve-se destacar que o sentido da tutela dos referidos bens jurídicos não é antecipar temporalmente a punibilidade, ${ }^{23}$ já que isso não teria sentido, mas sim que o que em verdade se dá é que a lesão ao "bem jurídico final" não consta ou é dificilmente demonstrável.

\footnotetext{
18 Horn, Konkrete Gefährdungsdelikte, 1973, p. 204 ss.; JAKOBS, (n. 14), p. 6/79.

19 LK- StGB/ Schroeder 11. ed. 1994, §16 Rn. 95; Sch-Sch/Cramer/Sternberg-Lieben StGB, 27. ed. 2006, § 15 Rn. 98 a.

20 Tribunal supremo (BGH) NStZ 1996, p. 83 ss.

21 WEBER, (n. 10), p. 23 ss.

22 Neste sentido Baumann/ Weber / Mitsch Strafrecht AT, 11. ed., 2003, p. 8 Rd. 42.

23 Nesta direção, RADTKE, Die Dogmatik der Brandstiftungsdelikte, 1998, p. 53 ss. Contrariamente JAKOBS,
} 
Dentro das afirmações fronteiriças encontram-se aquelas que sustentam a "criminalização na preparação da lesão de um bem jurídico" A "lesão do bem jurídico" pode se ler tanto no sentido passivo do bem jurídico como na ação do agente. Mas se repõe aqui a equivocada metáfora da "preparação", já que está tem una referência espacial e não é adequada ao conceito de lesão vinculado à ação e ao resultado.

III.

As metáforas anteriormente analisadas não seriam objeto de tão contundente crítica se as mesmas fossem meros jogos de palavras sem maiores conseqüências práticas, mas o certo é que o caso é outro. As mesmas, traduzidas em talhe militar ("fortificação", "muralha" "linha de defesa") colocam o direito penal em pé de guerra contra o inimigo, deixando-se ver, por conseguinte, como um verdadeiro "direito penal do inimigo" ${ }^{24}$ Diante disso, o ora homenageado pretende denunciar apenas uma parte desta ciência dedicada efetivamente ao inimigo, e desta maneira preservar que o outro direito penal, o do cidadão, não se perverta ao adotar uma sistemática similar. ${ }^{25}$

Convém aqui nos deter naquelas metáforas que significaram falsos motivos para a criação de tipos penais, o que ocorreu, por exemplo, com a punição da tentativa na "manipulação não autorizada de resíduos perigosos" ( $326 \mathrm{StGB}$ Código Penal da República Federal de Alemanha -), cuja fundamentação foi permitir interceptar o agente no mesmo momento em que se desfaz de resíduos de forma indevida (incluindo o caso em que se faça por meio de um veículo de carga). ${ }^{26}$ Sem embargo, a "interceptação" é um conceito que corresponde melhor à ação policial, e de nenhuma maneira pode ser incluída na ameaça psicológica que significa a proibição penal, como assim tampouco na já referida prevenção de execução. O que sucede é que a "interceptação" da conduta descrita é, como direito de política, já factível com a mera proibição penal do delito consumado. Conseqüentemente, uma "interceptação" própria da esfera do direito penal significa uma contradictio in adjecto.

com sua correta e original, ainda que híbrida, metáfora dos "flocos do injusto precocemente realizados" (ZStW, v. 97 [1985], p. 774).

24 Ainda mais militares e agressivas são, naturalmente, as cada vez mais recorrentes leis denominadas "lei de luta contra...". Contra elas, HASSEMER, Festschrift für Fr.- Chr. Schroeder, 2006 p. 51 e ss, 57; Kindhäuser, Ibidem, p. 81 ss., 95.

25 Entre outros, Fondations and Limits of Criminal Law and Criminal Procedure (An Anthology in Memory of Professor Fu-Tseng Hung, org. Yu-hsin Hsu), 2003, p. 41 ss., HRRS 3/2004, p. 88 e ss. Contra a denominação de "Direito Penal do inimigo" em nossa ciência, Gössel Festschrift für Fr:-Chr Schroeder, 2006, p. 35 ss., 46; Kindhäuser, Ibidem, p. 81 ss., 95. Contrariamente, por que ao se falar "Direito Penal do inimigo" seguimos falando de Direito Penal, Cancio Melia, ZStW, v. 117 (2005), p. 267 ss.

26 Projeto do Governo 16. St ̈̈G, BT- Drs. 8/2382, p. 19. 
Algo similar ocorreu no projeto da sexta grande reforma do código penal (StGB), em que se buscou justificar a punibilidade da tentativa no tráfico de menores com o fim de retirá-los do país, com o argumento de que o fato de adiantar o começo da investigação ao preâmbulo da consumação do delito, significaria, na medida do possível, evitar a efetiva retirada do menor do País. ${ }^{27} \mathrm{O}$ que se omite aqui é que evitar ilícitos não decorre de simples autorização, mas sim que se constitui, ademais em um dos principais deveres da polícia; por isso dizemos que neste caso as possibilidades do direito de polícia são muito mais apropriadas que a investigação processual penal. É lamentável que em um projeto de lei do governo possam aparecer erros tão grosseiros, o que demonstra, por outra parte, a irritante intenção de policializar cada vez mais o processo penal. É assombroso como já não se pode pensar a prevenção de delitos concretos nos limites do processo penal.

Não tão vistosa, mas igualmente equivocada é a fundamentação da punibilidade da tentativa no tratamento de menores ( $\$ 236,3 \mathrm{StGB}$ ): "para poder combater o tráfico de menores desde a primeira fase delitual" ${ }^{28}$ Conservando o vocabulário militar, apontaremos que tipos penais como este igualmente podem "combater-se em primeira fase" mediante a ameaça que significa a punição da consumação.

Por outro lado, a motivação da punição da tentativa no abuso de confiança consiste em que "é necessária a antecipação da proteção penal, sobretudo naqueles casos em que os danos se contam em milhões" ${ }^{29}$ Igualmente foi demonstrado que inocentes representações submetem indivíduos às garras dos agentes, ainda com a existência da ameaça penal. Também há que evidenciar aqui que, se bem esta proposta legal foi deixada de lado, isto apenas se deu por temor do surgimento de uma maré de falsas denúncias, assim como também pelas dificuldades probatórias que representava. ${ }^{30}$

Do mesmo modo foi fundamentada a incriminação da tentativa em lesões corporais com a intenção de fazer chegar a proteção penal ao estádio prévio, e assim melhor tutelar o bem jurídico em questão (integridade corporal). ${ }^{31}$ Poderíamos continuar citando casos no código penal vigente em que se pode observar uma indiscriminada punição injustificada da tentativa (99 faltas e 64 delitos $=163$, contra 19; e $96=115$, no ano de 1871), que é produto de uma falsa representação de sua eficácia.

\footnotetext{
BT- Drs. 13/8587, p. 39.

BT- Drs. 13/8587, p. 39.

BT- Drs. 13/8587, p. $43,13 / 8587$, p. 43

30 Exclamação proveniente do Ministério Nacional de Justiça, segundo Meinecke, Die Gestzgebungssystematik der Versuchsstrafbarkeit von Verbrechen im StGB, 2001, p. 107.

31 BT- Drs. 13/8587, p. 36.
} 
Tampouco aqui podemos omitir a menção daquelas vozes que repetem equivocadamente e com freqüência que mediante a punição dos delitos de perigo concreto se impede a produção da lesão.

Finalmente afirmaremos que as estudadas metáforas da "punibilidade na preparação" determinam o aumento da persecução penal das ações preparatórias. ${ }^{32}$ Particularmente inquietante é a classificação como delitos (veja-se o §30 StGB) de tipos penais que significam ações preparatórias materiais, como a falsificação de documentos. ${ }^{33}$ Da mesma maneira podemos assinalar que a estipulação da comissão pela integração a um bando que se associa para cometer (futuros) crimes, somado ao requisito do profissionalismo, concebida como a intenção de criar uma contínua fonte de ingressos, configura igualmente um "tipo penal antecipado". Por último, são típicos segundo o $§ 267$, 4 StGB para a comissão de um delito por meio da pertinência a um bando os requisitos do §30 StGB: compromisso e disposição, de tal forma que o $\S 267,4$ StGB se complementa com as exigências adicionais do $\S 30 \mathrm{StGB} .{ }^{34}$

Assim a fundamentação da sexta grande reforma (StrRG), BT- Drs. 13/7164, p. 43.

JAKOBS, (n. 12), p. 772.

34 O $\$ 267,4$ é, antes de tudo, exagerado e constitui, em verdade uma "qualificação aparente" E isso porque o profissionalismo na comissão do delito de associação ilícita já se encontra regulamentada no $\S 267,3, n$. 1 . 